\title{
简析地面自动气象站故障的判断与处理
}

周进 孙尚东 赵福东

凌海市气象局

DOI:10.32629/as.v2i3.1572

[摘 要] 综合气象观测是构建先进现代气象业务体系的基础。近年来,自动气象站的功能随着科学技术的发展得到了不断的 完善和提高, 而观测质量的高低首先是由设备性能决定的。观测台站业务人员的责任也发生了变化,其首要任务是保证自动化 设备的正常运行, 各级装备保障和业务管理人员需对自动气象站设备在使用过程中出现的故障进行分析、判断和处理, 保证自 动站的稳定运行率和数据可用率, 借以提升综合业务指数。本文包括的故障分析、维修方法、具体步骤等为重点, 一般性原理 从简。

[关键词] 自动气象站; 故障; 分析; 处理

\section{1 各类自动站故障类型分析与处理}

1.1 雨量传感器故障及处理方法 (以翻斗式雨量传感器 为例)

日常维护: 定期检查翻斗通道中是否有碎片、小虫、细 叶等, 入口和出口处是否有堵塞物。除去污物并清洁滤网。如 有必要, 漏斗表面可以用中性洗涤剂清洗, 但清洗后严禁用 手触碰翻斗内部。

故障处理范例 (1) : 滞后降水判断

某区域站, 当出现大的降水过程之后, 采集软件显示多 次出现大约每小时有 0.1 毫米滞后降水, 可以判定为雨量筒 内过滤网被柳絮等细小毛物堵住, 使雨水存在筒中, 不能及 时下流造成这种断续、分散性下流。

故障处理范例 (2) : 无降水数据

某次降水过程, 仅某站无降水数据, 可以判定除雨量传 感器堵塞外, 可能为干簧管损坏、雨量电缆线接头和端子处 有松动、接触不良或雨量线意外断裂。应立即带上相应工具 和设备前往维护。

故障处理范例 (3): 雨量超差

处理方法: 用模拟标准器对采集器进行校准, 确认采集 器通道是否正常; 用量杯量取 $10 \mathrm{ml}$ 水缓慢注入雨量筒承水 器, 查看是否显示值为 $15.6 \mathrm{~mm}$ 降水量; 直接用手翻动计数翻 斗 (即下翻斗), 用万用表电阻导通档直接量取输出信号, 导 通次数与翻动次数是否一致, 否则更换干簧管。

1.2 温度常见故障及处理方法 (以 HMP45D 温湿度传感器 为例)

Vadisala 生产的 HMP45D 型温湿度传感器可靠性较高, 温度一般不容易损坏。

故障处理范例 (1) : 温度示值与人工观测值偏差较大

当出现温度值与人工观测值偏差较大时, 首先清理或更 换传感器头部的过滤罩, 保证罩内外通气良好; 如测量值偏 差较大, 只能更换传感器内的温度测量板。

故障处理范例 (2): 温度示值为 0 或者负值

如果发现, 温度示值为 0 或者负值, 首先检测温度传感
器连接线是否虚接或松动。若连接正常, 可测量铂电阻温度 传感器的四根输出线之间的电阻值, HMP45D 型传感器使用的 PT100 铂电阻测温元件, 即 $0^{\circ} \mathrm{C}$ 时电阻为 $100 \Omega, 80^{\circ} \mathrm{C}$ 对应 $130.9^{\circ} \mathrm{C},-50^{\circ} \mathrm{C}$ 对应 $80.31 \Omega$, 若测量值明显超出电阻范围则 可以判定传感器故障。

故障处理范例 (3) : 更换传感器后, 数据仍不正常

若换上备份传感器后, 数据仍不正常, 而且检查电缆接 线正确, 则可判定为采集器故障, 此时需将采集器拿到厂家 检修或更换采集器。

1.3 湿度常见故障及处理方法 (以 HMP45D 温湿度传感器 为例)

HMP 45D 湿度传感器输出为 $0 \sim 1 V$ 直流电压输出, 对应相 对湿度为 $0 \sim 100 \%$ 。湿度传感器长期处在高湿环境中容易失 效, 若放到低湿环境中退湿可继续使用; 如不能恢复正常, 则湿度测量元件已损坏, 需要更换。

另外, 要定期检查传感器头部保护罩内的白色滤纸, 发 现污损后要及时处理 (蒸馏水洗净, 自然晾干) 或更换。

检测方法: 可在采集器湿度传感器输入端断开传感器后 直接用稳定恒压恒流源输入模拟湿度传感器 $0 \sim 1 V$ 直流电 源电压, 即可检查采集器湿度测量是否正常。(注意: 输入电 压不能超过所模拟传感器输出的极限值, 以免损坏采集器。)

1.4 气压传感器常见故障及处理方法 (以 PTB220 气压传 感器为例)

PTB220 型气压传感器可靠性高, 性能稳定, 气压表通过 RS232 通信口直接连接到采集器, 无需定期及预防性维护措 施。为保证 \pm 0.2 百帕的精度, 建议每年对照良好的便携标 准仪器检查一次。

故障处理范例 1: 出现突然无数据或者为 0 异常数据情况

首先查看传感器与采集器两端的 RS232 连接线是否松 动; 是否被人为的意外误接。可直接用计算机串口连接传感 器, 来检查传感器是否损坏。

如果没有回传数据则传感器有故障, 如果回传数据为乱 码则注意通信的波特率、数据位、停止位的设置是否正确。 


\title{
浅谈葡萄栽培管理技术
}

\author{
李利平 张英 秦胜波 \\ 河南省澲阳市南乐县自然资源局 \\ DOI:10.32629/as.v2i3.1567
}

[摘 要] 葡萄在我省市多个地区都有种植, 是农民增收致富的重要途径之一, 大部分地区的葡萄种植存在技术上的问题, 本文 从葡萄栽培技术和管理技术两方面入手,分析葡萄增产、提质的方式方法,为我国葡萄种植水平提高尽微薄之力。

[关键词] 葡萄; 栽培技术; 管理技术

\section{引言}

葡萄在各地均有栽培, 具有较高的经济价值。当前, 大部 分地区的葡萄种植尚存在技术问题, 果品质量差、再加上农 民过度追求产量, 导致葡萄整体质量和市场竞争力差, 减少 了农民种植葡萄的经济效益。

\section{1 葡萄园地选择和管理}

1.1 正确选择园址是决定葡萄栽培成败的关键因子

葡萄园土壤的营养结构、水分含量、根系生长空间等基础 保障直接关系到葡萄生长, 最适合葡萄生长的是土质疏松, 富 含有机质的沙壤土。因此, 应选择灌溉便利, 排水良好的地带。

\section{2 土壤深翻管理}

首先深翻可以改良土壤, 深翻结合施肥促进土壤团粒结 构, 提高土壤含水量, 增强土壤微生物含量与活动, 提高土壤 的肥力。其次, 深翻会切断部分老根, 促进萌发生活力更强的 新根, 增加根的密度, 增强吸收土壤养分的能力。并且能够使 植株枝蔓生长健壮, 有利于花芽的形成和产量的提高。

\section{3 中耕和除草}

中耕是葡萄生长期经常性的土壤耕作, 多在 5-9 月进行, 中耕深度在 5 厘米左右, 中耕可以保持土壤疏松, 改善土壤 透气性, 有利于根系和土壤微生物的活动。除草是一项重要 的田间管理工作, 仅在土壤表层进行。

\section{4 正确使用肥料}

葡萄栽培过程中的施肥需要根据葡萄在不同生长阶段的 需要进行, 采用穴施、沟施、冲施等多样化施肥方式, 尽量采 用分子较小的肥料进行使用, 充分提高葡萄植株对于肥料的 利用率, 缓解葡萄根腐病的发生和病况, 使葡萄植株健康生 长。基肥一般在秋后施入较好, 此时正是根系生长高峰, 伤根 又容易愈合, 促使发新根。首先是秸秆还田, 秸秆经过粉碎后 参与有机肥堆肥、腐熟后可以作为基肥进行利用, 也可以直接 撒入葡萄园做覆盖使用, 经过秸秆还田的葡萄园土壤湿度得 到有效提升, 肥力增加, 土壤板结情况有效下降, 有利于葡萄 的新一年生长。其次是生草肥田, 草经过光合作用可以将水
故障处理范例 2: 当气压测量数据偏差较大

要检查静压管及连通管路是否堵塞, 如静压管被机箱压 住等。在气压畅通的情况下, 气压测量数据仍然偏差较大, 需要重新校准气压传感器。

故障处理范例 3: 无气压测量数据

当传感器及连接线完好而采集器端没有气压测量数据 时, 可能是采集器串口损坏, 雷击会造成串口的损坏, 此时需 将采集器拿到厂家检修或更换采集器。

1.5 风传感器故障及处理方法

恶劣天气, 如: 冰霞、雷电、大风等可能损坏风传感器。 风传感器本身就是轴承传动传感器, 长时间工作可能会因轴 承磨损引起测量误差。此时传感器需做更换处理。

故障处理范例 1: 风向值出现明显错误

风向值出现明显错误时, 则在确定风向传感器电缆连接 没有问题的情况下, 用万用表直流档直接测量传感器的直流 输出信号, 风向测量的是风向传感器的直流 输出电压应为 $0 \sim 2.5 \mathrm{~V}$ 之间, 对应的角度为 $0 \sim 360^{\circ}$ 。具体操作: 将风向传 感器从风横臂上取下来, 用短线直接连接到万用表上, 转动 风向标的角度, 若数值明显不正常, 表明传感器损坏; 若此时
数值正常, 则连接到采集器上时显示的风向有误, 则可判定 为采集器故障。

故障处理范例 2: 风速值出现明显错误

风速传感器输出频率信号 $0 \sim 1221 \mathrm{~Hz}$, 最好用数字频率 仪或者可以测量频率的万用表测量, 若在电缆线没有故障且 有风速的实时情况下频率输出测量值为 0 , 则表示传感器损 坏; 若用仪器检测风速传感器输出频率数值正常, 连接到采 集器时系统显示风速有误, 则可判定为采集器故障。

在地面气象观测中, 只有正确判断自动气象站设备在运 行过程中其存在的问题, 科学合理的解决, 才能保证自动站 的稳定运行率和数据可用率, 借以提升综合业务指数。最终 为气象工作的开展提供可靠依据。

\section{[参考文献]}

[1]赵静.新型自动气象站运行故障及分析处理[J].时代 农机,2018,45(11):36.

[2]吴会洪,孙百安,姜水平.自动气象站故障分析与处理 实例[J].数字通信世界,2018,(06):262+260.

[3]朱玉新.自动气象站运行故障分析及维修处理[J].科 技风,2018,(32):133. 